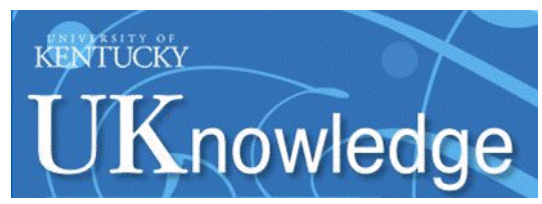

University of Kentucky

UKnowledge

11-18-2016

\title{
Dreams, Aspirations and Related Constructs in Children and Adolescents: A Literature Review
}

\author{
Daniel T. L. Shek \\ University of Kentucky \\ Florence K. Y. Wu \\ The Hong Kong Polytechnic University, China \\ Hildie Leung \\ The Hong Kong Polytechnic University, China
}

Follow this and additional works at: https://uknowledge.uky.edu/pediatrics_facpub

Part of the Child Psychology Commons, and the Developmental Psychology Commons

Right click to open a feedback form in a new tab to let us know how this document benefits you.

\section{Repository Citation}

Shek, Daniel T. L.; Wu, Florence K. Y.; and Leung, Hildie, "Dreams, Aspirations and Related Constructs in Children and Adolescents: A Literature Review" (2016). Pediatrics Faculty Publications. 276.

https://uknowledge.uky.edu/pediatrics_facpub/276

This Article is brought to you for free and open access by the Pediatrics at UKnowledge. It has been accepted for inclusion in Pediatrics Faculty Publications by an authorized administrator of UKnowledge. For more information, please contact UKnowledge@lsv.uky.edu. 
Dreams, Aspirations and Related Constructs in Children and Adolescents: A Literature Review

\section{Digital Object Identifier (DOI)}

https://doi.org/10.1515/ijdhd-2017-7004

Notes/Citation Information

Published in International Journal on Disability and Human Development, v. 16, issue 4, p. 359-366.

(C2017 Walter de Gruyter GmbH, Berlin/Boston.

The copyright holder has granted the permission for posting the article here. 


\section{Daniel T.L. Shek*, Florence K.Y. Wu and Hildie Leung}

\section{Dreams, aspirations and related constructs in children and adolescents: a literature review}

DOI 10.1515/ijdhd-2017-7004

Received July 25, 2016; accepted August 25, 2016; previously published online November 18, 2016

\begin{abstract}
Although children and adolescents are often asked about their "dreams" about life, scientific studies of "dreams" and related constructs are grossly inadequate. This paper describes the findings arising from a review study exploring the concepts of dreams, aspirations and related constructs in children and adolescents. Besides an overview of the concept of dream, conceptual features and unique underpinnings of other concepts commonly related to dream, such as "aspirations", "hope”, "future orientation" and "resilience" are presented in this paper. The research questions surrounding "dream" and related constructs in children and adolescents are presented and future research directions are discussed.
\end{abstract}

Keywords: aspirations; beliefs in the future; dreams; future orientation; hope.

\section{Introduction}

It is common for adults to ask children and adolescents what dreams they have. In primary and secondary schools, students are usually asked to write essays about their dreams and aspirations in life. However, when we asked whether the dreams of children and adolescents have been scientifically studied, two observations emerged. First, except the psychoanalytic literature on dreams, where

\footnotetext{
*Corresponding author: Daniel T.L. Shek, Associate Vice President (Undergraduate Programme) and Chair Professor of Applied Social Sciences, Faculty of Health and Social Sciences, Department of Applied Social Sciences, The Hong Kong Polytechnic University, Room HJ407, Core H, Hunghom, Hong Kong, P.R. China, E-mail: daniel.shek@polyu.edu.hk; Centre for Innovative Programmes for Adolescents and Families, The Hong Kong Polytechnic University, Hong Kong, P.R. China; Department of Social Work, East China Normal University, Shanghai, P.R. China; Kiang Wu Nursing College of Macau, Macau, P.R. China; and Division of Adolescent Medicine, Kentucky Children's Hospital, University of Kentucky, Lexington, KY, USA

Florence K.Y. Wu and Hildie Leung: Department of Applied Social Sciences, The Hong Kong Polytechnic University, Hong Kong, P.R. China
}

dreams are regarded as the "royal road to the unconsciousness", systematic investigations of dreams in children and adolescents are sparse in the scientific literature. Second, dreams in children and adolescents are not necessarily described in a positive manner, particularly in Chinese culture. Students who do not concentrate during class are labeled as "daydreamers". Young people who think big are also regarded as dreaming the impossible.

While few systematic research studies on the dreams of children and adolescents have been conducted, some related concepts such as aspirations, beliefs in the future and hope have been published. Benson [1] argued that developmental assets are "building blocks of healthy development that are essential for all youth, regardless of their background" (p. 24). For example, one of the developmental assets conducive for positive youth development is beliefs in the future, including the development of future potentials, choices, goals and options [2]. Particularly, Sun and Shek [3] asserted that "promotion of beliefs in the future for positive youth development deserves greater attention since there is growing research evidence demonstrating its positive effects on adolescent well-being” ( $p$. 6). They recommended the provision of a supportive environment to encourage adolescents to internalize both hope and optimism. Against this background, there is a need to systematically review the scientific literature on dreams and the related constructs such as aspirations, hope, resilience, belief in the future and future orientation of children and adolescents to understand what factors shape their formation and how they affect adolescent development.

With the financial support of the Bao Bao Bear Care Foundation Limited, a collaborative research study was conducted to understand the scientific underpinnings of instilling dreams, aspirations, hope, future orientation and related qualities in children and adolescents. The study attempted to investigate the positive impact of such constructs on children's and adolescents' wellbeing and overall development, as well as to review existing interventions based on the related constructs [4]. The Bao Bao Care Foundation was founded in 2008 following the Sichuan earthquake to facilitate the provision of programs to children in Sichuan. As children should not be deprived of experiencing a sense of hope despite adversity, the iDream initiative was established to inspire and encourage children to explore their dreams and to help 
ensure their positive future orientation. With an emphasis of exposing children to the success stories of various professionals, it is believed that children would be able to understand the life trajectory leading to success and generate hope for their own future.

Based on the final report [4], three papers are included in the present special issue. In this paper, the basic concept of dreams and related constructs such as aspirations and future orientation are discussed. The questions surrounding these concepts and the related observations are presented. Finally, the conclusions based on the literature review are highlighted. In the second paper, the methodology of the review and factors influencing dreams and related development are presented. The last paper discusses the existing interventions, instruments and consequences of these constructs on child developmental outcomes.

\section{Dreams and related constructs}

Walt Disney once said that "if you can dream it, you can do it". Disney's quote attempted to state the causal relationship between "dream" (the manifestation of beliefs in the future) and "do" (action-taking to actualize the "dreams"). However, the manifestation of these beliefs depends on "can" - an individual's ability to understand the unique meanings of "dream" to himself or herself, and the courage to create his/her own dream(s). Children and adolescents have often been claimed as "big dreamers." Yet the increasing trend of children and adolescents feeling despair and hopelessness hinders their boldness to "dream for the future" and threatens their holistic wellbeing and health [5]. Many educators, psychologists and professionals in human services have placed an increasing emphasis on how to nurture hope for the future in children and adolescents so that it helps to foster healthy development [6]. However, in both Western and Chinese contexts, there is limited research on intervention programs assisting children and adolescents in exploring the meaning of "dream" uniquely to them.

Although there is scarce research about "dream" with reference to future hope, there has been a bloom of research on related concepts to "dream", namely "hope", "aspirations", "future orientation", "resilience" and "beliefs in the future". It is therefore fundamental to explore the meanings of "dream" and the related concepts (hope, aspirations, future orientation, resilience and beliefs in the future) to children and adolescents, factors leading to the development of and possible outcomes of having developed these attributes in youth and effective interventions implemented to help youngsters nurture these hopes and aspirations in their life experiences. In this paper, we first outline the concepts found in the literature review.

\section{Dreams}

"Dreams" are a specialized area of psychoanalytic research in psychology. Freud, an advocator of researching dreams, stated that the functions of dreams "as the guardians of sleep" have two distinctive characteristics - "wish-fulfillment and hallucinatory experience" ([7], p. 131). The notion falls much into a psychologicalneurobiological perspective in understanding what the meaning "dream" is. There is scarce literature reviewing the concept "dream" apart from this framework. However, the idea of "dream" in recent research of hopes and aspirations sheds light on some new interpretations of the concept. "Dream" appears to mean an individual's wish for the future and shares certain commonalities with the concepts of "hope" or "beliefs in the future" to manifest an individual's goals or beliefs in the present $[5,8]$. In the study of Juvakka and Kylmä [5], the researchers investigated the meaning of hope in adolescents with cancer and the concept "dream" was often brought up by adolescent patients. The adolescents expressed their understanding of "dream" as "extended toward the future quite far away and they relate (dreams), for example to studying and getting married and having children" or "being able to travel or having a boyfriend or a girlfriend" (p. 195). The "dreams" adolescents shared in the study were like the Freudian explanation of "wish-fulfillment" yet no concrete plans or pathways were suggested (or not knowing how) to actualize these wishes. The wish to "study" and "establish a family" in their sharing, however, does engender hope in adolescents and exhibits their beliefs in the future.

"Dream" is "meng-xiang" in Chinese and it comprises "wish" and "dream" ("meng") and "thinking" ("xiang"). The "xiang" could be the imagined wishes ("xiang-xiang") or the cognitive process of actualizing the goals ("li-xiang"). In the Chinese context, no scientific study has been conducted to examine the concept of "dream" in adolescents. In Li's [9] action research, he assured the importance of pursuing children's own dreams in developing their moral values. The dreams to be pursued are "peer dreams" (the shared dream in adolescents), "great people dreams" (the nurturance of leadership), "China dreams" (civic responsibility) and "world dreams" (the contribution made to 
the world). Though each dream is not explicitly explained in this action research, the "dream" for Chinese children and adolescents is not limited to individual pursuit but is combined with cultural and national contexts.

\section{Aspirations}

In their conceptual review, Quaglia and Cobb [10] asserted that aspiration consists of two components: inspirations and future ambitions. "Inspiration" is experienced when an activity is perceived to be enjoyable and exciting. One is aware of being immersed in the here and now of life. "Ambition" is characterized by the perception that a particular activity is meaningful toward the pursuit of a future goal. Based on the social cognitive career theory, Rojewski [11] suggested that self-efficacy beliefs and external socialization patterns including gender, socioeconomic status and culture, as well as the internalization of learning experiences are important sources for aspirations. Thus, aspirations may be seen as inspiration served to motivate students toward their ambitions. Nurmi [12] explained the psychological processes of aspirations as motivation, planning and evaluation. Motivation pertains to "what" future interests adolescents may have (i.e. goal-setting based on values and interests). Planning is about "how" one may achieve their prescribed goals (i.e. developing strategies). Evaluation is to do with assessing the possibility or extent that the goals may be actualized. Aspiration has long been perceived as a crucial psychological aspect of "a student's propensity toward post-secondary education and college attendance" and has been defined as the "educational and vocational dreams that students have for their future" ([13], p. 346). This notion emphasizes the role of aspiration in helping children and adolescents in achieving educational attainments and successes in their school and post-school years. Scholars have found that aspirations contribute significantly to educational and occupational achievements of children and adolescents $[14,15]$ and there are numerous studies investigating the relationship between academic outcomes and aspirations, e.g. [13, 16, 17].

However, some scholars have suggested that aspirations could be perceived from a developmental perspective and conceived them as future-oriented representations of what individuals strive for in various life domains [18]. The meaning of the concepts "success" and "achievement" for children and adolescents is not only limited to academic attainments, but is also extended to other facets of life achievements. Aspirations or "career aspirations" may help elucidate many important career development choices one makes across a lifespan (e.g. deciding on education pathways and making career-related choices) and how one perceives the availability of resources and the impact of social forces on one's career or life opportunities [11].

\section{Hope}

There are numerous studies on the concept of "hope" in various professional arenas (e.g. psychology, theology, mental health and medical science). The theory of hope advocated by Snyder and his colleagues [19] has aroused much attention in recent literature. Snyder [20] defined hope as "a positive motivational state that is based on an interactively derived sense of successful agency (goaldirected energy) and pathways (planning to meet goals)" (p. 8). The theory proposed by Snyder and his colleagues [19] gives equal emphasis to both the "agency" and "pathways" and states that an individual's hope level is not only dependent on how one realizes his/her own goals ("pathways"), but also on one's perceived ability ("agency") to achieve those goals. This theory has influenced much of the recent research in conceptualizing hope to investigate if hope (one's agency and pathways) is relatively constant or hope levels fluctuate with a given situation [21].

Hope is conceptually distinct from other strengthbased constructs like optimism [22] and self-efficacy [23]. Although both hope and optimism focus on positive happenings in the future, optimism refers to the belief that "good rather than bad things will happen" ([22], p. 219) and hope puts this belief into action and generates plans for the future. Bailey et al. ([24], p. 168) explained this by noting that "[o]ptimism theory posits that outcome expectancies determine goal-directed behavior, whereas hope theory posits that efficacy expectancies (agency) are equally necessary determinants of goal-directed behavior".

Hope is a motivational construct found to be related to various positive outcomes in children, adolescents and adults [25]. High-hope children and adolescents have been found to have expectations of success where obstacles are perceived as "temporary" and a high level of goaldirected motivation allows impediment to be channeled toward "the best alternative way" [26]. Psychologists have found empirical evidence to support that hope is related to positive outcomes among youth including higher levels of goal-directed thinking [19], better use of coping strategies and higher task performance [27, 28].

Despite attention to an individual motivation to sustain hope in life, little attention has been given to how 
contextual assets help shape hope during childhood and adolescence [29]. Te Riele [30] conceptualized hope in terms of four practical resources: (a) a focus on the possibility, (b) critical reflection of life's opportunity, (c) a community of hope and (d) a positive culture for hope to thrive. These four resources affirm the interdependence of individual strength (an individual's perception of possibilities and reflections) and the ecology (significant others and the culture) around the youth to nurture hope in children and adolescents. Yohani [8] observed that hope could be nurtured in the context of caring relationships from significant others. In addition, for children, caregivers' ability to devise ways for goal attainment is crucial to hope and adaptation [26]. These caring and hopeful experiences of children and adolescents within their ecology are important predictors of hope during adolescence [31].

Factors engendering hope in children and adolescents are worth exploring with reference to their physical, psychological or mental well-being and different cultural contexts. More research is warranted to better understand the conditions under which hope may operate and bring positive impact as a psychological strength. For instance, future studies may investigate the interactions between hope and different life experiences of children and adolescents [6].

\section{Future orientation}

According to Seginer and Shoyer [32], future orientation is an umbrella term encapsulating different aspects of future thinking and the subjective image that one may have regarding a future time point. Future orientation relates strongly with the concepts "hope" and "aspiration". It is not to be mistaken with prediction of the future, but rather what one hopes for (or wishes not to happen) in the future. Future orientation is a complex and multidimensional process [12]. It comprises an individual's motivations, cognitive representations (to visualize what the "future" is) and behavioral components. Seginer and Shoyer [32] have stated explicitly the importance of "behavioral components". There are two variables indicating the "behavioral components" - "exploration" and "commitment". The process of exploration helps one to determine the extent to which one's personal abilities, values, environmental circumstances or social expectations are aligned with future options [33]. The individual is seeking advice and information regarding their future options in this process. "Commitment" results in "a sense of knowing where one is going" [34] and the resolution to pursue a particular option. It is about continuity of the belief and concrete action-taking to pursue the options. Both variables are instrumental to children's and adolescents' future orientation toward future goal achievement.

Future orientation is particularly important in early adolescence $[35,36]$. During this transitional developmental stage, youth are often confronted with situations where they are required to make choices. For instance, they may be tempted to experiment with sex or drugs or to choose their peers [37]. In the face of these situations, the ability to look ahead to the future and speculate how present decisions or behaviors may result in consequences in the future become increasingly vital to successful navigation in this developmental phase. McCabe and Barnett [38] contended that while youth do evaluate the realism of their future plans, particularly in terms of their career development, they lack the skills to generate plausible solutions to overcome obstacles that may interfere with the achievement of their goals, specifically family- or relationship-related goals. Therefore, better communication and more assistance should be provided to help children and adolescents understand what "future" means and guide them in searching for their pathways.

Future orientation represents images of the futurerelating experiences or events subsumed under different life domains [39]. Cross-cultural studies have found that adolescents are mainly concerned with career, romantic relationships and family (e.g. establishing a family with their spouse) domains in life [35]. However, most of the studies have primarily focused on adolescents' understanding of future educational or career achievement. This focus is consistent with findings about "aspirations" and "hopes". Many present intervention programs, as a result, are exclusively focusing on examining youth's career and educational plans but ignoring the establishment of relationships and family plans. Future research may focus on investigating children's and adolescents' perceptions of and the difficulties encountered in relationship-building and establishment of families. Moreover, outcome studies may include variables such as academic achievement and positive psychological and social adjustment.

\section{Resilience}

Research on resilience has been heavily focused on developmental psychopathology in the past few decades. Resilience has gained much attention from research about positive psychology in recent decades and there has been a shift of focus to investigating the relationships between resilience and positive youth development [40, 41]. It 
relates to the concepts "optimism," "faith and hope" and "sense of self" [42]. Resilience is characterized by one's inclination to overcome rather than succumb to the effects of risks [36,43]. It emphasizes individuals' strengths rather than vulnerabilities [44]. Resilience is exhibited when one acknowledges the presence of risks, adversities and challenges and willingly adapts or copes with the situation $[45,46]$. Resilience is understood to be a result of negotiations between individuals who identify themselves as physiologically, psychologically and mentally healthy and their environments in conditions collectively viewed as adverse [44]. In other words, an individual's resilience develops in response to challenges, not in their absence, and the individual has then the capacity and capability to face these challenges.

In the comprehensive literature review of Khanlou and Wray [44], resilience is regarded as a multidimensional concept and is (a) a process (rather than a single event), (b) a continuum (rather than a binary outcome) and (c) likely a global concept with specific dimensions. When resilience is perceived as a "process", it develops over time; depending on the interactions between systems involved, the time period can vary across individuals and settings. As a continuum, the same individual can be in different parts of the continuum of resilience depending on the available support systems (e.g. family, school or community) and challenges faced over time.

Resilience can also be experienced as a global process, and there are specific domains of resilience such as academic resilience or social resilience. Lee et al. [41] summarized the existing literature of the definition of resilience in the review and proposed that three components, "capacity", "process" and "results", should be encompassed in defining the concept. The concepts "capacity" and "process" share some commonalities with the propositions of Khanlou and Wray on "process" and "continuum". The component "result" is defined as the positive and beneficial outcomes resulting from successfully navigating stressful events ([41], p. 2).

Although the concept "resilience" has been investigated and explored for several decades, Alperstein and Raman [47] observed that research has predominantly focused on physical health and less on determinants of mental health concerns at the macro-level, "and even less on emotional well-being and enhancing 'coping' or promoting resilience" (p. 269). Thus, it is recommended to conduct research on resilience and evaluations on interventions of the role of resilience in promoting mental health.

\section{Beliefs in the future}

There is scarce literature conceptualizing "beliefs in the future" in both Western and Chinese contexts. Catalano et al. [40] defined "beliefs in the future" as "an internalization of hope and optimism about possible outcomes" (p. 107), in which the concept "beliefs in the future" entails the concepts of "hope" and "optimism". Based on the definition suggested by Catalano et al. [40], Sun and Lau [48] stated that the concept includes two components: (a) goal-directed thoughts, that is to set achievable goals and pursue the goals with possible pathways and (b) goal-directed motivation, which is self-efficacy derived from positive self-appraisal. The thoughts and motivations reciprocally influence each other and "rejuvenate" [3] when the goals are successfully achieved. In addition, these two components encompass some common features with the concepts of "hope" (the goals for the individual), "aspirations" (the motivation of pursuit) and "future orientation" (the wish that the individual would like to accomplish). The concept "beliefs in the future" has been used interchangeably with the concepts "hope" and "future orientation".

The above discussion outlines a brief conceptual review of the concept of dream and the related constructs. The review shows that most of the concepts share some common features conceptually yet each concept has also some unique underpinnings. The concepts under review are thus evidently all crucial to children's and adolescents' development.

\section{Questions to be considered and future research directions}

According to $\mathrm{Wu}$ et al. [4], with reference to the concept of dream and related constructs, several categories of questions should be raised for consideration. The first category of questions is related to the basic concept of dream and the related constructs. There are several questions that researchers and practitioners should consider:

1. What are the psychological, physiological and social processes, steps and paths that lead to the achievement of a dream? If so, how and when?

2. What is the importance of practicality in leading children successfully to their dreams?

3. Should the "appropriateness" of a dream be considered? If so, at what stage of development? 
4. Is it advisable to do a reality check on dreams of youth? Does this limit their future orientation or keep them from experiencing disappointment?

Regarding the factors that influence the development of dreams and related constructs, several questions should be asked:

1. What motivates students to have a dream?

2. At what age is future orientation in children likely to be seen? What contributes to delays or absence of future orientation?

3. Should aptitude and intellectual ability be considered in helping a child achieve his or her dream? If so, at what stage of development?

4. What barriers do youth normally run into when trying to achieve their dreams? When they face challenges/ barriers, what are the components that help these young people overcome them?

5. How can teachers and schools support their students? What are their roles?

6. How can peers support one of their own? What is their role?

7. Do parents influence youth's dreams? How can parents support their children? What is their role? What happens if the child's dream is not in line with the parent's dream for their child? How to come to a resolution?

Concerning the consequences of having dreams and related attributes, the following questions should be asked:

1. Why is it good to have a dream? What are the general and specific benefits?

2. What happens if one does not have a dream?

3. How will the youth's dream help other people, the community and the society at large?

Finally, for the existing interventions from the Western and Chinese contexts, the first two questions are raised:

1. Should there be active intervention to shift the focus of a child's dream? If so, at what stage of development?

2. Is the assessment of talents, ability, passion and interest important in helping children achieve their dreams? If so, how should this be done?

As we focus on the concept of dream and the related constructs in this paper, we will discuss the first category of questions. For the other categories of questions, they will be addressed in the second paper and in the third paper. Regarding the first question (i.e. processes and pathways), the review conducted by $\mathrm{Wu}$, Leung and Shek [4] shows that there are very few developmental models to state clearly the processes, steps or paths that lead to the development of a dream. In fact, there are unique ways for each individual to achieve his or her dreams, which might be influenced by the psychological, physiological and social factors.

For the other questions, most of the existing literature emphasizes the possibility of the children and adolescents in searching for their own dreams or aspirations. Some scholars cautioned the "practicality", with a strong emphasis on academic excellence, or "appropriateness" (for example the parental or societal expectations) might hinder the motivation and willingness of the Chinese youth to search for their own future. Although some of the children or adolescents will evaluate the realism of their future plans, the search for the possibility is the "essence" perceived by the youth when they search for future dreams and the "reality check" might limit their orientation.

In view of the paucity of research on the concept of dream and related constructs, Wu, Leung and Shek [4] proposed several directions for future research in terms of theoretical conceptualization of the concept of dream and the related constructs. First, there is scarce literature conceptualizing the idea "dream", yet the usage of "dream" related to the concepts of "hope", "aspirations" and "future orientation" is immensely common in the media. The interchangeable usage of "dream" and "hope" or "aspirations" suggests that theoretically there is a need to provide a clearer differentiation among the concepts. Empirical studies may be conducted to delineate the unique psychological constructs that differentiate the concepts from each other. The theoretical and research literature on "dream" reflects little consensus about definitions, with scarce well-developed conceptualization and operationalization of the concept. We believe that concerted attention could be given to justify strategies used to operationalize the concept and it is crucial for the investigators to exercise caution in the use of terminologies.

Second, earlier conceptualizations and research on the constructs have focused predominantly on the individual. In more recent years, conceptualizations and investigations have moved beyond the level of the individual to include other influential factors such as peers and parents. Future research may adopt an ecological approach to examine factors on the individual, family, school and community levels that may impact on children's and adolescents' hope, dreams, aspirations and future orientation. This research would allow for more holistic and comprehensive theoretical models and shed light on the psychological underpinnings of the constructs. 
Acknowledgements: The current project was financially supported by The Bao Bao Bear Care Foundation Limited. The materials in this paper are based on the unpublished report entitled "Literature Review on Hope and Aspirations in Children and Adolescents" submitted to the Foundation. The authorship is equally shared by the authors.

\section{References}

1. Benson PL. All kids are our kids: what communities must do to raise caring and responsible children and adolescents. San Francisco, CA: Jossey-Bass, 2006.

2. Catalano RF, Hawkins JD, Berglund ML, Pollard JA, Arthur MW. Prevention science and positive youth development: competitive or cooperative frameworks? J Adolesc Health 2002;31:230-9.

3. Sun RC, Shek DT. Beliefs in the future as a positive youth development construct: a conceptual review. ScientificWorld] 2012;2012:527038.

4. Wu FK, Leung H, Shek DT. Collaborative research report on "Literature review on hope and aspirations in children and adolescents". [Unpublished manuscript] Hong Kong: Department of Applied Social Sciences, The Hong Kong Polytechnic University, 2015.

5. Juvakka T, Kylmä J. Hope in adolescents with cancer. Eur J Oncol Nurs 2009;13:193-9.

6. Valle MF, Huebner ES, Suldo SM. An analysis of hope as a psychological strength. J Sch Psychol 2006;44:393-406.

7. Freud S. Introductory lectures on psycho-analysis. S.E., 15/16. London: Hogarth Press, 1916-1917.

8. Yohani S. Nurturing hope in refugee children during early years of post-war adjustment. Child Youth Serv Rev 2010;32:865-73.

9. Li J. "Please let children develop through pursing their dreams": a study of children's moral development in Hongze county primary school. Jiangsu Educ Res 2013;17:30-3.

10. Quaglia RJ, Cobb CD. Toward a theory of student aspirations. J Res Rural Educ 1996;12:127-32.

11. Rojewski JW. Occupational aspirations: constructs, meanings, and application. In: Brown SD, Lent RW, editors. Career development and counseling: putting theory and research to work. New York: John Wiley, 2005:131-54.

12. Nurmi JE. How do adolescents see their future? A review of the development of future orientation and planning. Dev Rev 1991;11:1-59.

13. Gil-Flores J, Padilla-Carmona MT, Suárez-Ortega M. Influence of gender, educational attainment and family environment on the educational aspirations of secondary school students. Educ Rev 2011;63:345-63.

14. Hill NE, Castellino DR, Lansford JE, Nowlin P, Dodge KA, Bates JE, et al. Parent academic involvement as related to school behavior, achievement, and aspirations: demographic variations across adolescence. Child Dev 2004;75:1491-509.

15. Marjoribanks K. Family contexts, individual characteristics, proximal settings, and adolescents' aspirations. Psychol Rep 2002;91:769-79.

16. Patton W, Creed P. Occupational aspirations and expectations of Australian adolescents. Aust J Career Dev 2007;16:46-59.
17. Sirin SR, Diewer MA, Jackson LR, Gonsalves L, Howell A. Future aspirations of urban adolescents: a person-in-context model. Int J Qual Stud Educ 2004;17:437-56.

18. Salmela-Aro K, Kiuru N, Leskinen E, Nurmi JE. School burnout inventory (SBI) reliability and validity. Eur J Psychol Assess 2009;25:48-57.

19. Snyder CR, Harris C, Anderson JR, Holleran SA, Irving LM, Sigmon ST, et al. The will and the ways: development and validation of an individual-differences measure of hope. J Pers Soc Psychol 1991;60:570-85.

20. Snyder CR. Hypothesis: there is hope. In: Snyder CR, editor. Handbook of hope: theory, measures, and applications. San Diego, CA: Academic Press, 2000:3-21.

21. Lloyd TJ, Hastings R. Hope as a psychological resilience factor in mothers and fathers of children with intellectual disabilities. J Intellect Disabil Res 2009;53:957-68.

22. Scheier MF, Carver CS. Optimism, coping, and health: assessment and implications of generalized outcome expectancies. Health Psychol 1985;4:219-47.

23. Bandura A. Self-efficacy mechanism in human agency. Am Psychol 1982;37:122.

24. Bailey TC, Eng W, Frisch MB, Snyder CR. Hope and optimism as related to life satisfaction. J Posit Psychol 2007;2:168-75.

25. Edwards LM, Ong AD, Lopez SJ. Hope measurement in Mexican American youth. Hisp J Behav Sci 2007;29:225-41.

26. Truitt M, Biesecker B, Capone G, Bailey T, Erby L. The role of hope in adaptation to uncertainty: the experience of caregivers of children with down syndrome. Patient Educ Couns 2012;87:233-8.

27. Onwuegbuzie AJ, Snyder CR. Relations between hope and graduate students' coping strategies for studying and examinationtaking. Psychol Rep 2000;86:803-6.

28. Peterson SJ, Gerhardt MW, Rode JC. Hope, learning goals, and task performance. Pers Individ Diff 2006;40:1099-109.

29. Callina KS, Johnson SK, Buckingham MH, Lerner RM. Hope in context: developmental profiles of trust, hopeful future expectations, and civic engagement across adolescence. J Youth Adolesc 2014;43:869-83.

30. Te Riele K. Philosophy of hope: concepts and applications for working with marginalized youth. J Youth Stud 2010;13:35-46.

31. Padilla-Walker LM, Hardy SA, Christensen KJ. Adolescent hope as a mediator between parent-child connectedness and adolescent outcomes. J Early Adolesc 2011;31:853-79. .

32. Seginer R, Shoyer S. How mothers affect adolescents' future orientation: a two-source analysis. Jpn Psychol Res 2012;54:310-20.

33. Lewin K. Field theory and experiment in social psychology: concepts and methods. Am J Sociol 1939;44:868-96.

34. Erikson EH. Identity: youth and crisis. New York: WW Norton, 1968.

35. Greene AL. Future-time perspective in adolescence: the present of things future revisited. J Youth Adolesc 1986;15:99-113.

36. Rutter M. Psychosocial resilience and protective mechanisms. Am J Orthopsychiatry 1987;57:316-31.

37. Dryfoos JG. Adolescents at risk: prevalence and prevention. New York: Oxford University Press, 1990.

38. McCabe KM, Barnett, D. The relation between familial factors and the future orientation of urban, African American sixth graders. J Child Fam Stud 2000;9:491-508. 
39. Nuttin J, Lens W. Future time perspective and motivation: theory and research method. Leuven: University Press and Lawrence Erlbaum Associates, 1985.

40. Catalano RF, Berglund ML, Ryan JA, Lonczak HS, Hawkins JD. Positive youth development in the United States: research findings on evaluations of positive youth development programs. Ann Am Acad Pol Soc Sci 2004;591:98-124.

41. Lee TY, Cheung CK, Kwong WM. Resilience as a positive youth development construct: a conceptual review. ScientificWorld] 2012;2012:390450.

42. Edward K-L. Resilience: a protector from depression. J Am Psychiatr Nurses Assoc 2005;11:241-3.

43. Ager A. Annual research review: resilience and child wellbeing-public policy implications. J Child Psychol Psychiatry 2013;54:488-500.
44. Khanlou N, Wray R. A whole community approach toward child and youth resilience promotion: a review of resilience literature. Int J Ment Health Addict 2014;12:64-79.

45. Masten AS. Resilience in developing systems: progress and promise as the fourth wave rises. Dev Psychopathol 2007;19:921-30.

46. Masten A, Herbers J, Cutuli J, Lafavor T. Promoting competence and resilience in the school context. Prof School Couns 2008;12:76-84.

47. Alperstein G, Raman S. Promoting mental health and emotional well-being among children and youth: a role for community child health? Child Care Health Dev 2003;29:269-74.

48. Sun RC, Lau PS. Beliefs in the future as a positive youth development construct: conceptual bases and implications for curriculum development. Int J Adolesc Med Health 2006;18:409-16. 